\title{
BEYOND THE NEWSLETTER
}

In the last issue of this Newsletter to appear under the Editorship of Professor B. Mittman, the founding President of ICCA, an expression of gratitude is due to its long-time devoted Editor. When thanking him, one cannot help admiring his versatility. Combining the Editorship with being the ICCA President, he was an inspiration to many researchers, and stimulated computer chess not only in the United States, but also in Europe. With Professor M. Newborn, he organized World Computer Chess Championships in Stockholm, Toronto, and Linz, and is now working on the Fourth Championship in New York.

In order further to strengthen the European wing of ICCA, Professor Mittman decided to look for the next Editor on that continent. His choice finally fell on Jaap van den Herik of the Delft University of Technology. The University authorities felt honoured and were willing to assume responsibility for continuing the publication, provided a high scientific level would be achieved, suggesting that the Newsletter should change its name to ICCA Journal, and that an Editorial Board should be established.

The Board of ICCA agreeing, as from the next issue the ICCA Journal will be published under the aegis of an Editorial Board. Those sought out by the Editor designate, Prof. dr. I. S. Herschberg (Delft University of Technology) and Prof. dr. T. A. Marsland (University of Alberta), agreed to serve. Quite possibly the Editorial Board will eventually be expanded.

\section{A New Policy}

Inevitably, all this implies that a new editorial policy will evolve. Such a policy will not run counter to the interests of the present readership. The coverage will continue to appeal to all those now reading the ICCA Newsletter, but will be extended to embrace research articles. It is hoped to foster the Journal in its new role as a vehicle for the meeting of minds in computer chess, be they established authorities or relative newcomers to the discipline.

\section{Some Contributions Refereed}

As a consequence of the policy, research contributions (and only those) will be subject to a refereeing process. For the first few issues, refereeing will be informal and by members of the Editorial Board and should generally cause no appreciable delay in publication.

It is accepted that it is only natural for a new Journal not to lay down hard and fast standards for its refereeing; norms will, it is hoped, evolve as time goes on. It is intended to appoint a Panel of Referees, their names to be published in the Journal as and when appropriate.

4

Research contributinns need not report final results; notes of work-inprogress will be welcomed. The scope of these contributions comprises computer chess and its interfaces with all related domains, notably its bearing on Artificial Intelligence and Computer Science. Special techniques and progress in chess theory due to computer programs are included. Under these headings, the reporting of improvements on the $\alpha-\beta$ algorithm or novel 
theoretical chess results are cordially invited. It would be useful, though by no means a condition for publication, that research contributions offer an incitement for knowledgeable chess players to take an interest in computer chess, as especially theoretical novelties are bound to do.

\section{The Journal's Broad Scope}

Beyond the refereed articles, the Journal will be open to whatever is likely to be of interest to its present readership. Next to editorials, there will be information from the ICCA, announcements of conferences and tournaments, reports on them and annotated computer chess games.

Reviews and abstracts of the recent computer chess literature will also be a permanent feature of the Journal. Dr. Marsland has kindly undertaken to act as the reviewer-in-chief. His task would be greatly facilitated if readers would forward their publications, including theses and significant internal memoranda, to him (see box on page 4).

At this point of our provisional policy statement, it should be stressed again that the Journal is open to all comers with relevant contributions to the field, including those of a topical, personal or polemical interest. Except for book reviews as noted above, contributions should be addressed to the Editor designate, H. J. van den Herik (see box on page 4).

\section{The Near Future}

For the first few issues only minimal specific guidelines are imposed on the authors, except that contributions are limited to no more than 4000 words:

- chess diagrams when helpful should be included

- all notation must be algebraic, with $\mathrm{N}$ for Knight

- authors of major contributions may be requested to supply cameraready copy on forms to be supplied by the Editor

- for shorter contributions, Delft University has kindly made available the services of Ms. J. Pesch, who will do any reformatting required.

For the near future, four issues per annum are envisaged. Computer chess researchers of acknowledged standing have submitted some contributions for the first few issues and have committed themselves to further articles. This overwhelmingly positive response to the Editor's request ensures that the first issues will be worthwhile. However, this should not be taken to mean that additional contributions will find no place in these issues. On the contrary, we reiterate that, from its first issue onwards, the ICCA Journal firmly intends to be the world-wide prime focus for all those desirous to publish their findings where they are most likely to reach their co-workers in this admittedly specialized field.

The Editorial Board:

H. J. van den Herik, Editor designate

I. S. Herschberg, member

T. A. Marsland, member 